Open Access

Original Article

J Nurs Explor 2021 Jan;1(1):15 . https://doi.org/10.29252/jnexp.1.1.15

\title{
Family experiences of burn patients: A content analysis study
}

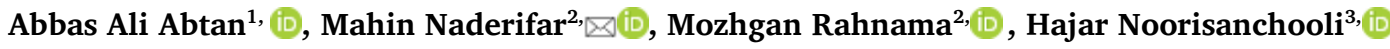 \\ 1 Student Research Committee, Nursing and Midwifery School Zabol University of Medical Science, Zabol, Iran \\ 2 Nursing Department, School of Nursing and Midwifery, Zabol University of Medical Sciences, Zabol, Iran \\ 3 Nursing Department, School of Nursing and Midwifery, Zahedan University of Medical Sciences, Zahedan, Iran
}

Purpose: This study aimed to explain the family experiences of burn patients. Methods: This was a qualitative study with a conventional content analysis approach. Purposeful sampling was performed with nine burn patients admitted to the burn unit of Amir Al-Momenin Ali Hospital in Zabol, Iran, in 2019. The data were collected using a semi-structured in-depth interview. The data analysis process is performed according to the steps proposed by Graneheim and Lundman. The rigor and trustworthiness of the data were checked, and the ethical standards of the research were considered. Results: Two main categories were extracted, including the two-sided presence of the spouses (spouse encouraging presence, spouse care presence) and the two-sided presence of families (supportive family presence and family care presence). Conclusions: The experiences of burn patients showed that burn patients were encouraged by the presence of their spouses and families. Therefore, the significant presence was identified as the essence of family experiences of burn patients under study and the need to support family members is suggested.

Keywords: Burn, Family, Patients, Spouses

$\square$ Corresponding: naderifar@zbmu.ac.ir; Received: October 29, 2020; Accepted: November 11, 2020; Published: January 1, 2021; This article is available on https://www.jnexp.ir

\section{Introduction}

Severe burns lead to distress not only in the injured person but also in their family members [1]. In fact, the occurrence of any disease in the members can bring the family into crisis and have negative consequences for the family, such as socio-economic effects. The families may have to take on new roles. They may experience issues such as inadequate support, multiple stressors, high levels of anxiety, inadequate communication patterns, inability to express emotions, and inadequate problem-solving skills while caring for patients [2]. However, family members and the others paying attention to the patients can increase survival and improve the quality of life [3]. In other words, the quality of life of patients with burns is positively correlated with family support [4].

As there is a few studies that have focused on the lived experiences of burn survivors, the significant role of the family in caring for, and improving the quality of life of the patients $[3,4]$, and the different reaction of the families to the burns complications, this qualitative study was conducted to explain the family experiences of burn patients on through the content analysis.

\section{Methods}

\section{Ethical approval}

Ethical principles in the research were approved by the research ethics committee of the Zabol University of Medical Sciences, Iran (IR.ZBMU.REC. 1398. 180). The researcher obtained a permission letter and offered to the hospital management. The participants signed a consent form for recording the interviews, maintaining confidentiality, and the authority to leave the study. 


\section{Study design/Setting}

The present qualitative study, conventional content analysis, was examined the experiences of burn patients who admitted to the burn ward of Amir Al-Momenin Ali Hospital in Zabol, Iran.

\section{Participants}

Nine burn patient were selected from a purposive sampling [Table 1].

\section{Data measurement/ collection}

Data collected using a semi-structured in-depth interview with open-ended questions. Including, "Talk about your family experiences after the burn? How has your family life changed after the burn?" During the interview, the researcher helped participants share their experiences without giving direction. Exploration questions were also used if necessary. The interviews took place in a quiet environment. Each interview was 45-60 minutes, depending on the circumstances and the patience of the participants in one or two sessions.

\section{Analyses}

All interviews were typed, verbatim, reviewed, coded, and immediately analyzed by the researcher. In fact, data analysis was performed simultaneously and continuously with data collection. Data collection was continued until the data were saturated. The criterion for achieving data saturation was the lack of access to new concepts and codes in subsequent interviews. Data analysis was performed using the conventional content analysis approach. In this approach, in the beginning, each interview was carefully read to gain an initial understanding, underlined the important statements and recorded as codes (initial coding). For the initial coding, the words of the participants themselves and the signifying codes (researcher perceptions of the statements) were used. The codes, which were conceptually similar to each other, were then summarized to clarify the meaning and classified into categories and subcate- gories. The data analysis process was performed according to the steps proposed by Graneheim and Lundman [5].

\section{Rigor and trustworthiness}

In order to achieve the rigor and trustworthiness, the resulting codes and concepts were consulted and reviewed with experts and collaborators of the research project. Besides, several colleagues were asked to codify some parts of the text of the interviews and then the coding agreement was investigated. To confirm the transferability of the findings, it was tried to use patients with different demographic characteristics and different experiences and the researcher assessed all aspects of behaviors, events and living experiences. The confirmability of the findings was achieved by a rich description of the researcher from all stages of the research; In addition, the details of the research were carefully documented to enable the evaluation of external observers. Participants were given the text of coded interviews to confirm their compliance with their experiences, and in some cases, corrections was made.

\section{Results}

Analysis of data collected from participants led to the extraction of three main categories (Table 2).

\section{The two-sided presence of spouses}

\subsection{Encouraging presence of spouse}

The experiences of burn patients showed encouragement in the presence of their spouses at the hospital (Table 2). A married man with $20 \%$ of second-degree burns stated: "My wife, who sat behind the door of the burn unit day and night, was a great encouragement to me and made me endure the pain and suffering of the burn."

A 26 -year-old female patient with $30 \%$ of second-degree burns on the face and limbs reported:

"After the burn, my husband tried not to make me feel deficient; he was all over me and comforting me."

\subsection{Presence of spouse care}

Burn patients were satisfied with their spouse's care (Table 2). A 30 -year-old woman with $25 \%$ burns on the face, hands and chest declared: "many nights when I was asleep, my husband was awake and by my side. He would 


\begin{tabular}{|c|c|c|c|c|c|c|c|c|}
\hline No & $\begin{array}{l}\text { Age } \\
(\mathrm{yr})\end{array}$ & Gender & $\begin{array}{l}\text { Marital sta- } \\
\text { tus }\end{array}$ & $\begin{array}{l}\text { Education } \\
\text { level }\end{array}$ & Job & $\begin{array}{l}\text { Size of burn } \\
\text { (\%) }\end{array}$ & $\begin{array}{l}\text { Degree of } \\
\text { burn }\end{array}$ & Area \\
\hline 1 & 30 & Male & Married & Bachelor & Employee & 20 & 2 & Face and hands \\
\hline 2 & 50 & Male & Married & Associate & Retired & 25 & 2,3 & Face and hands \\
\hline 3 & 26 & Female & Married & Bachelor & Housewife & 30 & 2 & Face, hands, and foot \\
\hline 4 & 49 & Female & Married & Primary & Housewife & 25 & 2 & $\begin{array}{l}\text { Hand, foot, and abdo- } \\
\text { men }\end{array}$ \\
\hline 5 & 29 & Female & Married & Bachelor & Housewife & 30 & 2,3 & Face, hand, foot \\
\hline 6 & 48 & Female & Married & Secondary & Housewife & 15 & 2 & Face and hand \\
\hline 7 & 30 & Female & Married & Diploma & Housewife & 25 & 2,3 & Face, chest, and hand \\
\hline 8 & 28 & Male & Married & Diploma & Mechanic & 20 & 2 & Hand and foot \\
\hline 9 & 21 & Male & Single & Associate & Student & 30 & 2,3 & Hand and foot \\
\hline
\end{tabular}

Table 2. The main category, categories, subcategories, and codes

\begin{tabular}{|c|c|c|c|}
\hline Main category & Category & Subcategory & Code \\
\hline \multirow[t]{4}{*}{ Effective presence } & $\begin{array}{l}\text { The two-sided presence of } \\
\text { the spouse }\end{array}$ & $\begin{array}{l}\text { Encouraging presence of } \\
\text { spouse }\end{array}$ & $\begin{array}{l}\text { Understanding the endless love of the spouse; Mutual support of the pa- } \\
\text { tient and the spouse during the hospitalization; The patient enjoying the } \\
\text { spouse's attention and comfort; Feeling the patient's suffering and pain } \\
\text { with the presence of the spouse; The presence of the patient's spouse the } \\
\text { sweetest moments during hospitalization; The spouse tried to hide the ef- } \\
\text { fects of the patient's burn; The spouse tried to calm the patient; The wife } \\
\text { gave hope; My wife gave me more time than she could }\end{array}$ \\
\hline & & Spouse care presence & $\begin{array}{l}\text { Patient satisfaction with spouse nursing; Satisfaction with spouse accom- } \\
\text { panying during treatment; Spouse support and accompanying the cause } \\
\text { of faster wound healing; Spouse physical care; Patient spouse psychologi- } \\
\text { cal care in the treatment process }\end{array}$ \\
\hline & $\begin{array}{l}\text { The two-sided family pres- } \\
\text { ence (mother; father; chil- } \\
\text { dren; siblings) }\end{array}$ & Family support presence & $\begin{array}{l}\text { No leaving the patient alone at home; Care for children by the mother } \\
\text { during the hospitalization; a brother after the burn accompanies financial } \\
\text { assistance for treatment by father; Patient support by each family mem- } \\
\text { ber; Encouragement to the children during the hospitalization; Encour- } \\
\text { agement of the brothers after the burn; Comprehensive parental support; } \\
\text { The patient; The brother is ready to help the patient financially; The chil- } \\
\text { dren try to resolve the patient's upset; The patient is accompanied by the } \\
\text { children during the burn; The family pays for the treatment; The patient } \\
\text { supports the father after the burn; Encouragement to be patience by the } \\
\text { family; The support of the children the cause of inspiration; The mother } \\
\text { of the patient and the patient's constant Companion of mother after the } \\
\text { burn; The brothers' companionship and financial support of the patient; } \\
\text { My father after the burn was like a mountain behind me }\end{array}$ \\
\hline & & Family care presence & $\begin{array}{l}\text { Children trying to soothe a burn mother; Mother trying to strengthen and } \\
\text { heal the patient; Accompanying mother and wife in feeding the patient; } \\
\text { Children wanting parents to continue treatment in a better medical cen- } \\
\text { ter; Children caring for parents during hospitalization; Patient satisfac- } \\
\text { tion with child care; Satisfaction of the patient with the attention of sib- } \\
\text { lings during hospitalization; The presence of the patient's sister when ad- } \\
\text { mitted to the burn ward; Meeting the patient's nutritional needs by chil- } \\
\text { dren; Family support with the patient in treatment and restoring beauty; } \\
\text { Children pursuing to eliminate the effects of burns }\end{array}$ \\
\hline
\end{tabular}

bring me a bedpan when I needed to go to the bathroom. I often told my husband that I would not be improved if you were not here."
2. Two-sided presence of family (mother, father, children, siblings)

\subsection{Family support presence}

The experiences of burn patients showed that they enjoyed the help of their family members (father, mother, 
siblings and children) during the illness (Table 2). A 26year-old woman with $30 \%$ burns on the face and limbs presented: "After the burns on the days when my wife went to work, one of my sisters or brothers would come to me so that I would not be alone."

A 30-year-old woman with $25 \%$ burns on the face, chest and hands stated:

"My mother is always worried about me. She came and walked with me all the time I was in the hospital, bringing me food."

\subsection{Presence of family care}

Burn patients were satisfied with the nursing of family members (father, mother, siblings, and their children) (Table 2). A 49-year-old woman with $25 \%$ of seconddegree burns in the hands, feet and abdomen reported: "My children support me in every way. While I was hospitalized, I didn't feel any shortage in terms of food because they provided me with whatever I wanted."

\section{Discussion}

This study reflects the family experiences of burn patients. Based on these experiences, they enjoyed and were satisfied with the encouraging presence of their spouse, supportive presence, and family members, i.e., father, mother, siblings, and children. Studies have shown that regular presence of family members at the patient's bedside reduces anxiety in burn patients [6] and family involvement can be used as one of the nonpharmacological methods along with pharmacological methods to reduce anxiety caused by pain in burn patients [7]. Patients' families face many stressors during their care period, which trigger their physical and psychological reactions [8]. However, it can be expected that the family members of these patients have also experienced anxiety. In fact, the hospitalization of a family member can cause anxiety and psychological problems in other members [9].
The presence of caring for the spouse and family members of burn patients was another family experience of burn patients. This presence probably had a significant impact on the recovery process of the patients. In this regard, studies show that family social support is an effective and cost-effective strategy to adapt to burn complications [4]. Family emotions can positively or negatively affect the improvement of the disease and their responses [3]. Moreover, contrary to the common belief that the presence of family members leads to interference in the treatment process, the patient can be allowed to attend the patient's bedside at the request of the patient. Therefore, training nurses in order to get help from family members to accompany and calm the patient is critical [10].

\section{Conclusion}

Presence and support of the spouses and the other family members help the burn patients feel the fast recovery. Therefore, the effective presence was identified as the essence of family experiences of burn patients under study.

\section{Author contributions}

Conceptualization: AAA, MN. Formal analysis: MR. Methodology: AAA, MN, MR. Writing - original draft: AAA, MN. Writing - review \& editing: MR.

\section{Conflict of interest}

No declared.

\section{Funding}

None.

\section{Acknowledgments}

This article is extracted from a master's thesis in Medical-Surgical of Nursing. The authors would like to express their gratitude to the Zabol University of Medical Sciences and the patients who participated in and helped in this research. 


\section{References}

[1] Backstrom J, Willebrand M, Sjoberg F, Haglund K. Being a family member of a burn survivor- Experience and needs. Burns Open 2018; 2: 193-198.

[2] Motaghi M, Assadisharif F. Experiences of family from caring patient suffering from truma: A qualitative study. J Clinic Nurs Midwif 2016; 5(4): 90-100.

[3] Panahi M, Tazakori Z, Karimollahi M. Challenges of patients of daughters with Multiple Sclerosis: A Phenomenological study. J Health Care 2018; 20(2): 165-176.

[4] Niromand-Zandi K, Atashrazm Jirandeh T, AtashzadehShoorideh F, Hoseinabadi-Farahani MJ, Talebi E, Bolourchifard F. Relationship between socio-familial support with satisfaction of body image in patients with burn. Iran Psychiatr Nurs 2016; 3(4): 1-9.

[5] Graneheim UH, Lundman B. Qualitative content analysis in nursing research: Content, procedures and measures to achieve trustworthiness. Nurs Edu Today 2004; 24(2): 105-12.

[6] Kherad M, Afrasiabi Z, Sadeghimehr R. Investigate the effect of family visit on sleep quality and anxiety of hospitalized burn patient in Ghotbeddin hospital at 2015. Psychol Model Method 2017; 8(30): 193-204.

[7] Koohi M, Bagheri-Nesami M, Esmaeili R, Mousavinasab SN, Hosseini SH. Effect of family participation in primary care provision to reduce pain anxiety among burn ICU patients. J Masandaran Univ Med Sci 2017; 26(146):88-99.

[8] Pashaee F, Taleghani F, Tavakol Kh. Family experiences from caregivering of patient with coronary artery bypass surgery: A qualitative study. Iran J Nurs Res 2010; 5(16): 61-71.

[9] Navidian A, Sarhadi M, Kykhaie A, Kykhah R. Psychological reactions of family members of patients hospitalized in critical care and general units compared with general population. Iran J Nurs 2014; 26(86): 16-28.

[10] Mehrnejad N, Navidhamidi M, Rezayee Hemami M, Ganji T, Ardeshiri M, Fathi P. The effect of family presence at the bedside on serum cortisol levels and physiological indexes in patients hospitalized in intensive care unit. Cardiovascular Nurs J 2014; 2(4): 36-42.

"Cite: Abtan A, Naderifar M, Rahnama M, Noorisanchooli H. Family experiences about burn patients: A content analysis study. J Nurs Explor 2021 Jan;1(1):15.

https://doi.org/10.29252/jnexp.1.1.15 